\title{
Thin-film composite membrane on a compacted woven backing fabric for pressure assisted osmosis
}

\author{
Soleyman Sahebi ${ }^{\mathrm{a}}$, Sherub Phuntsho ${ }^{\mathrm{a}}$, Leonard Tijing ${ }^{\mathrm{a}}$, Gang Han ${ }^{\mathrm{b}}$, Dong Suk Han ${ }^{\mathrm{c}}$, Ahmed \\ Abdel-Wahab ${ }^{c}$, Ho Kyong Shon ${ }^{\text {a* }}$
}

${ }^{a}$ Centre for Technology in Water and Wastewater, School of Civil and Environmental Engineering, University of Technology Sydney (UTS), PO Box 123, 15 Broadway, NSW 2007, Australia.

${ }^{\mathrm{b}}$ Department of Chemical and Biomolecular Engineering, National University of Singapore, Singapore 117585, Singapore

${ }^{\mathrm{c}}$ Chemical Engineering Program, Texas A\&M University at Qatar, PO Box 23874, Doha, Qatar

* Corresponding author: Email: Hokyong.Shon-1@uts.edu.au

\begin{abstract}
:
The water flux in forward osmosis (FO) process declines substantially when the draw solution (DS) concentration reaches closer to the point of osmotic equilibrium with the feed solution (FS). Using external hydraulic pressure alongside the osmotic driving force in the pressure assisted osmosis (PAO) has been found effective in terms of enhancing water flux and even potentially diluting the DS beyond osmotic equilibrium. The net gain in water flux due to the applied pressure in the PAO process closely depends on the permeability of the FO membrane. The commercial flat sheet cellulose triacetate (CTA) FO membrane has low water permeability and hence the effective gain in water flux in the PAO process is low. In this study, a high performance thin film composite membrane was developed especially for the PAO process through casting polyethersulfone (PES) polymer solution on a compacted woven fabric mesh support followed by interfacial polymerisation for polyamide active layer. This PAO membrane possesses a water flux of $37 \mathrm{~L} \mathrm{~m}^{2} \mathrm{~h}^{-1}$ using $0.5 \mathrm{M} \mathrm{NaCl}$ as DS and deionised water as the feed at an applied hydraulic pressure of 10 bar. Besides, the membrane was able to endure the external hydraulic pressure required for the PAO process owing to the embedded backing fabric support. While the membranes with low structural parameters are essential for higher water flux, this study shows that for PAO process, polymeric membranes with larger structural parameters may not be suitable for PAO. They generally resulted in compaction and poor mechanical strength to withstand hydraulic pressure.
\end{abstract}

Keywords: Forward osmosis, Pressure assisted osmosis, Thin-film composite membrane, Backing fabric support, Structural parameter 


\section{Introduction}

Forward osmosis (FO) has drawn significant research attention as an alternative membrane process for desalination, osmotic energy generation and treating impaired water sources [1-4]. Unlike pressure-based membrane processes such as reverse osmosis (RO) and nanofiltration (NF), FO utilises the osmotic pressure generated by draw solution (DS) as a driving force to transfer water across a semipermeable membrane without the need of hydraulic pressure [5]. However, since the osmotic pressure is based on concentration difference, the water flux decrease in the FO process is due to cumulative decline in the DS concentration $[1,6,7]$. Water flux occurs until the osmotic pressure of the DS attains equilibrium with the feed solution (FS) $[4,8]$.

Recently, combined processes of applied hydraulic pressure and osmosis have been reported with an attempt to exploit the synergies of the two processes in a single stage to overcome low flux in the FO process even generating water flux beyond osmotic equilibrium point [9-11]. The concept of pressure assisted osmosis (PAO) is in fact a hybridisation of the FO process and the RO process where the intrinsic loss of osmotic driving force in the FO process is supplemented by the external hydraulic pressure applied to the FO system. Therefore in the PAO process, external hydraulic pressure is applied to the feed side to enhance the water flux [11]. Several earlier works have demonstrated that the applied hydraulic pressure can increase the FO process performance $[11,12]$; however, the performance also closely depends on the characteristics of FO membranes including its water permeability, structural properties, mechanical strength, etc. [10].

To date, most of the published articles dealing with osmotic processes such as FO, pressure retarded osmosis (PRO) and particularly PAO are based on use of commercialised CTA-FO membrane with embedded woven polyester support mesh from HTI [11, 12]. Most other studies are reported using lab-scale fabricated membranes but for FO and PRO studies only 
[13-15]. Although CTA was the most commercially available FO membranes however, the low water flux associated with the CTA membrane is the most common issue in many studies $[10,11]$. Although it has been reported that Hydration Technology Inc. (HTI) has commercialised thin film composite (TFC) FO membrane, it is still largely unavailable to the researchers yet. One exception is a study by Coday et al. in which TFC from HTI has been used in addition to the CTA membrane for assessing the PAO process [10].

The TFC-FO membranes can be made with or without any backing fabric support and membranes prepared without a backing support are generally more efficient than those with backing fabric as its presence contributes towards enhanced internal concentration polarisation (ICP) effect that lowers the water flux during the FO process. Nevertheless, the membrane needs adequate mechanical strength to perform sustainably under certain hydraulic pressure and the function of the backing fabric is mainly to provide mechanical strength of a TFC membranes. This could be true even in the normal FO process where pressure drop could automatically occur in large-scale modules. Most recent efforts for fabricating high performance TFC-FO membrane have been widely devoted to modifying the structural morphology and chemical properties of the polymeric support layer in order to enhance the membrane performance by reducing ICP effects. These lab-made TFC-FO membranes without any fabric support have shown enhanced water flux and salt rejection compared to the commercial CTA-FO membrane or the TFC membranes $[16,17]$. However, most of these membranes are generally not effective in the PAO process due to the likely membrane compaction and low mechanical strength when subjected to hydraulic pressure $[16,17]$.

Based on casting procedures of the FO membrane on a large commercial-scale, the TFC membrane for the FO seems to have been fabricated in a similar way to that of the CTA-FO membrane [18]. The polymer solution is casted on a roll, which is followed by pulling the fabric from the top to embed it in the casted polymer solution. This unique fabrication method 
for the FO membrane confines the polymer penetration to the back of the porous fabric support and prevents the formation of air bubbles [18]. The polymer solution is first casted onto a rotating drum and then the woven fabric mesh is pulled onto the polymer solution from the top so that the backing fabric is fully embedded without formation of air bubbles and defect points [18]. This approach is adopted to prevent the penetration of polymer solution during casting thereby preventing wrinkle formation and substrate defects.

Tiraferri et al. have presented the successful reinforcement of FO membrane with highly porous non-woven PET fabric support using a RO style (conventional method) in the lab environment $[19,20]$. In this approach of synthesis, the backing fabric support was placed on the roll and then the polymer solution was poured on the top of the fabric support and casted by a casting blade on top of the roll. Another study by Qiu et al. also applied the commercial scale FO membrane casting method for fabricating embedded FO membrane on a woven fabric using polyamide-imide (PAI) material through phase inversion [21]. In order to limit polymer penetration and wrinkle formation for producing large pieces of defect and wrinkle-free membrane substrate, Mc Ginnis, and Mcguregan [18, 22] have used bilayer backing fabric to make the support layer sturdier and thicker. The use of bilayer backing fabric can block the polymer solution from penetrating the backing layer and limit the wrinkle and defect problems. Furthermore, Sairam et al. presented a method to prevent polymer penetration and formation of air pocket while fabricating cellulose acetate based FO membrane supported by woven mesh fabric at a lab scale level. The backing fabric is pasted with polyvinyl pyrrolidone (PVP-K60) on the glass plate where it can prevent polymer bleeding to the backing fabric and limit the formation of air bubbles during phase inversion [23].

The present work is therefore aimed to develop an effective TFC membrane tailored for PAO process by incorporating a woven mesh backing fabric into the polyethersulphone (PES) substrate formed by phase inversion. This study adopted unique approaches for embedding 
woven mesh fabric to the PES membrane support layer by applying both the conventional and commercial scale FO membrane fabrication methods to produce a wrinkle and defect-free TFC-FO membrane for PAO application. The properties of the TFC-FO membranes including their substrate morphologies and physical characteristics were investigated, and compared to two commercial FO membranes: commercialised CTA-FO membrane from HTI and the recently commercialised polyamide-based TFC-FO membrane (WJ-FO) from Woongjin Chemicals (now Toray Chemicals Korea). Commercial TFC-RO membrane from Woongjing Chemicals (WJ-RO) was also used for comparison.

\section{Materials and Methods}

\subsection{Chemicals and materials}

Polyethersulfone (PES) granules (Mn: 55,000 - Good fellow, UK) and polyester mesh woven fabric (PETEX 07-11/5, 07-40/25, SEFAR Pty. Ltd, Australia) were used for preparing the membrane substrates. 1-methyl-2-pyrrolidinone (NMP, anhydrous, 99.5\%) and Polyethylene glycol (PEG, MW 400) from Sigma-Aldrich Pty. Ltd, Australia were used in the casting solution. Chemicals used for interfacial polymerisation included m-phenylenediamine (MPD > 99\%), 1,3,5-benzene tricarbonyl trichloride (TMC, 98\%) and n-hexane (Sigma-Aldrich Pty. Ltd, Australia). CTA-FO membranes obtained from HTI (Albany, OR) and the FO and RO membranes from Woongjin Chemicals, Korea were used for comparison and validation purposes.

\subsection{Fabrication of flat-sheet TFC-PAO membranes}

\subsubsection{Casting PES membrane substrates by phase inversion}

The PES membrane substrates were prepared by casting PES polymer solution on the fabric support layer. As summarised in Table 1, a total of five different membrane samples were fabricated, and the PES polymer concentration ranged from 12-18\%. Two woven polyester 
fabrics with different opening percentage (5\% and $25 \%$ ) were used where membrane substrates $\mathrm{T}_{1}$ and $\mathrm{T}_{2}$ were prepared on the support fabric with $25 \%$ open area while the rest $\left(\mathrm{T}_{3}, \mathrm{~T}_{4}\right.$ and $\mathrm{T}_{5}$ ) were prepared on supporting fabric with 5\% open area. Two different casting approaches were used for preparing a PES support layer by phase inversion on top of the support layer fabric. The first method is termed here as FO-style casting method in which the polymer solution was casted onto a glass plate and then the woven fabric was pulled onto the polymer solution from the top. This approach of membrane fabrication is somewhat similar to the technique used for fabrication of FO membrane at commercial scale. This method was used for casting $T_{1}$ membrane sample. All other membrane samples in this study ( $T_{2}$ to $T_{5}$ ) were fabricated by adopting RO-style casting method in which the backing fabric was firstly placed on the glass plate and the polymer solution was poured on the top and then casted using a casting knife. The detailed compositions of the casting solutions for all the five membrane samples are summarised in Table 1.

Table 1. Summary for the synthesis of support layer of the various membrane samples prepared in this study

\begin{tabular}{|c|c|c|c|c|c|}
\hline \multirow[t]{2}{*}{$\begin{array}{l}\text { Membrane } \\
\text { sample ID }\end{array}$} & \multirow[t]{2}{*}{$\begin{array}{l}\text { Backing } \\
\text { fabric open } \\
\text { area }(\%)\end{array}$} & \multicolumn{3}{|c|}{$\begin{array}{l}\text { Composition of substrate } \\
\text { layer for phase inversion }\end{array}$} & \multirow[t]{2}{*}{$\begin{array}{c}\text { Fabrication methods } \\
\text { adopted }\end{array}$} \\
\hline & & PES (wt \%) & NMP (wt \% & PEG (wt \%) & \\
\hline $\mathrm{T}_{1}$ & 25 & 18 & 72 & 10 & FO-Style \\
\hline $\mathrm{T}_{2}$ & 25 & 18 & 72 & 10 & RO-Style \\
\hline $\mathrm{T}_{3}$ & 5 & 18 & 72 & 10 & RO-Style \\
\hline $\mathrm{T}_{4}$ & 5 & 18 & 62 & 20 & RO-Style \\
\hline $\mathrm{T}_{5}$ & 5 & 12 & 88 & -- & RO-Style \\
\hline
\end{tabular}

*Note: Woven polyester mesh fabric for all fabricated samples was $60 \mu \mathrm{m}$ in thickness. 
The casting solution was prepared by dissolving PES in NMP and PEG under constant stirring at $60{ }^{\circ} \mathrm{C}$ for 24 hours. The polymer dopes were then degassed for 1 hour using digital bench top ultrasonic cleaners (Soniclean Pty Ltd, Australia) and stored in a desiccator for at least 48 hours before casting. Casting was then performed on a glass plate using a stainless steel film applicator (Sheen Instruments Ltd, UK) with an adjustable gate height fixed at $200 \mu \mathrm{m}(\sim 8$ mils). The substrate after casting was immersed immediately into a precipitation bath of deionised (DI) water at room temperature to initiate phase inversion and remained in the bath for at least 10 minutes. The resultant substrate was then stored in water before undertaking the formation of an active rejection layer by interfacial polymerisation.

\subsubsection{Formation of polyamide rejection layer}

The polyamide rejection layer of TFC membranes was formed by interfacial polymerisation on the top surface of the PES membrane substrate based on the method widely reported [17, 24]. MPD solution was $3.4 \mathrm{wt} \%$, reaction time was 2 minutes and $0.15 \mathrm{wt} \%$ of TMC was used in n-hexane solution.

\subsection{Membrane characterisation}

\subsubsection{Characterisation of membrane morphology, contact angle, porosity and tensile} strength

Membrane cross-section and surface morphologies were examined using a high-resolution Schottky Field Emission Scanning Electron Microscope (SEM, Zeiss Supra 55VP, Carl Zies AG, Germany) operated at $10 \mathrm{kV}$. The membrane samples were first dried in a vacuum at room temperature for $24 \mathrm{~h}$. To view the cross sections of the membranes, samples were then flashfrozen in liquid nitrogen to preserve the pore structure. The presence of stiff woven fabric mesh 
support makes it difficult for a decent cut thus a sharp razor blade was used. All samples were sputter coated with thin layer of carbon before SEM imaging using Balzers Sputter coater (SCD 050, BAL-TEC, Germany).

The contact angles of the membranes were measured with the sessile drop method, using an Optical Tensiometer (Attension Theta Lite 100, Biolin Scientific, Finland). Membrane samples were dried in a vacuum at room temperature for $24 \mathrm{~h}$ before contact angle measurement. DI water droplets $(6 \mu \mathrm{L})$ were applied onto a levelled membrane surface and profile of the water drops were captured by a camera and the imaging software was used to determine the contact angles. At least 3 measurements were obtained to get the average values of the contact angles.

Membrane porosity $(\varepsilon)$ was obtained by measuring the dry mass $\left(\mathrm{W}_{2}\right)$ and wet mass $\left(\mathrm{W}_{1}\right)$ of the membrane sample (after subtracting the mass of the supporting mesh) and calculated based on the following equation [25] :

$$
\varepsilon=\frac{(W 1-W 2) / \rho i}{\left[\frac{W 1-W 2}{\rho i}\right],+[W 2 / \rho m]} \times 100 \%
$$

where $\rho i$ and $\rho m$ are the density of the wetting solvent (Isopropanol ethanol in the current study) and membrane, respectively. Tensile strength was evaluated using an Instron benchtype tensile test machine (LR5K Plus, maximum load limit of $100 \mathrm{~N}$ ) according to ASTM D882-10 with the crosshead speed adjusted to $5 \mathrm{~mm} / \mathrm{min}$. At least five dog-bone-shaped specimens for each fabricated membrane sample were tested, and the average of these was used as the tensile property for each sample.

\subsubsection{Measurement of pure water permeability and rejection properties}

All the membrane tests including the pure water peremeability ( $A$ value), PAO and FO processes were conducted using a FO cell similar to the cell used in our previous work [26]. 
For memebrane tests in the RO mode, the channel on the DS side of the membrane cell was filled with six layers of diamond shaped polystyrene spacers to prevent membrane deformation and damage due to applied hydraulic pressure on the feed side. For determining the $A$ value of the membrane, the membrane was tested in RO mode with DI water as feed and at applied pressure of 1-10 bar. A pressure pump was used for the FS side and the applied hydraulic pressure adjusted manually using the pressure valve and a bypass valve. The pure water flux $\left(J_{w}\right)$ was determined by measuring the changes in the volume of the DS tank connected to a digital mass balance data logging system and a PC using the following equation:

$$
\mathrm{A}=\frac{\mathrm{Jw}}{\Delta \mathrm{p}}
$$

where $\Delta p$ is the applied pressure and $J_{w}$ is the permeate water flux. The pure water permeability of the embedded substrate was also determined using the same approach.

The $\mathrm{NaCl}$ rejection of a membrane was measured using under $\mathrm{RO}$ mode at 10 bar using $10 \mathrm{~g} / \mathrm{L}$ $\mathrm{NaCl}$ solution as FS except for membrane samples T5 and WJ-FO where the applied pressures were 5 bar and 2 bar respectively using $1 \mathrm{~g} / \mathrm{L} \mathrm{NaCl}$ because they were not able to withstand higher pressures. Rejection was determined based on conductivity measurement (Ultra Meter IITM 4P, Myron L Company, CA) of the feed and permeate and calculated using the following equation.

$$
R=\frac{C f-C p}{C f} \times 100 \%
$$

where $C_{f}$ and $C_{p}$ are the salt concentrations in the feed and the permeate, respectively.

The salt permeability $(B)$ of a membrane was calculated according to the following equation [27]:

$$
B=\frac{A(1-R)(\Delta \mathrm{p}-\Delta \pi)}{R}
$$


where $\Delta p$ is the applied pressure and $R$ is the salt rejection of the membrane during the rejection test in the RO mode, $\Delta \pi$ is the osmotic pressure difference across the membrane.

\subsubsection{Determining the membrane structural parameter}

Membrane structural parameter $(S)$ is one of the critical properties of any osmotic membranes and is given by the following relationship that depends on the support layer thickness $(t)$ and tortuosity $(\tau)$ and its porosity $(\varepsilon)$ :

$$
S=\frac{t \tau}{\varepsilon}
$$

In the experimental tests, the membrane effective structural parameter can be determined using the empirical equation. Based on the classical ICP model developed by Loeb et al. [28], the water flux in the FO process is represented by the following equation:

$$
J_{w}=\frac{D}{S}\left[\ln \frac{A \pi_{D, b}+B}{A \pi_{F, b}+J w+B}\right]
$$

where $D$ is the bulk diffusion coefficient of the draw solute, $\pi_{F, b}$ and $\pi_{D, b}$ are the bulk osmotic pressures of the FS and DS respectively. Based on equation 6, the membrane support structural parameter is determined using the following equation:

$$
S=\left(\frac{D}{J_{w}}\right) \ln \frac{A \pi_{D, b}+B}{A \pi_{F, b}+J_{w}+B}
$$

\subsubsection{Membrane performaannce tests under PAO process}

All PAO experiments were performed under FO mode configurations: active layer facing FS (AL-FS) at $25{ }^{\circ} \mathrm{C}$ with pressure applied on the feed side of the membrane using the same membrane cell. The active layer facing DS (AL-DS or PRO mode) orientation was ignored because of possible damage to the active layer of the membrane as a result of a rejection layer collision with the spacer in the PRO mode. $\mathrm{NaCl}$ solutions of $0.11,0.5,1$ and $2.0 \mathrm{M}$ concentrations were used as DS. The FS contained either $10 \mathrm{~g} / \mathrm{L} \mathrm{NaCl}$ or DI water with the 
applied pressure varying between 0 and 10 bars and the maximum pressure rating for the pump was only up to 11 bars. The reverse diffusion of the draw solutes was evaluated by observing the electrical conductivity (EC) using a multimeter (CP-500L, ISTEK, Korea) when DI is used as feed. In this study, to validate the derived water flux produced by the fabricated TFC-PAO membrane, a commercial cellulose triacetate (CTA-ES) FO membrane (Hydration Technology Inc., Albany, OR) and TFC-FO and TFC-RO membranes from Woongjin Chemicals were tested under the PAO mode at different ranges of applied hydraulic pressures. The thermodynamic properties of the solutions such as osmotic pressure, viscosity, diffusion coefficient, density, etc. were analysed using thermodynamic modelling software OLI Stream Analyser 3.2 (OLI Systems Inc., Morris Plains, NJ, US).

\section{Results and discussion}

\subsection{Membrane substrate layer}

\subsubsection{Role of polymer concentration, backing fabric properties and casting method on membrane support structure formation}

Lower polymer concentrations have been used to fabricate substrate membrane with fingerlike pore structures to improve membrane porosity and thereby enhance solute diffusivity within the support layer of the FO membrane [19, 29, 30]. Although such approach has been reported to much lower the ICP effects, it also proportionately weakens the mechanical strength of the membrane [31]. Increasing the polymer concentration however may result in the loss of both the finger-like pore structure and membrane overall porosity, resulting in enhanced ICP effects and lowered membrane performance in the FO process [22]. Membranes with poor mechanical strength are not suitable for the PAO process since the driving force in the PAO process is a combined osmotic pressure difference and hydraulic pressure. Therefore, the 
membranes for the PAO process must be able to withstand the compressive and tensile force due to the presence of hydraulic pressure.

All the membrane support layers in this study was prepared using a woven polyester fabric mesh as the backing fabric. Two types of woven mesh backing fabric with similar thickness of $60 \mu \mathrm{m}$ but of different open area (5\% and 25\%) were used as shwon in Table 1 . The membrane support layer for $\mathrm{T}_{1}$ and $\mathrm{T}_{2}$ were prepared using backing fabric with $25 \%$ open area. The $\mathrm{T}_{1}$ sample was however fabricated by adopting FO-style casting method to solve a polymer penetration problem while the $\mathrm{T}_{2}$ sample was fabricated by the RO-style casting method. The $\mathrm{T}_{1}$ membrane shows a wrinkle free morphology and also appears to be defect free. However, a detail investigation revealed that large pores were formed on the substrate skin layer, making it unsuitable for the formation of thin and uniform rejection layer by interfacial polymerisation. This issue is more discussed later under the characterisation in Section 3.2.

Figure 1(a) shows the images of the $T_{2}$ membrane sample fabricated on the woven mesh fabric with a $25 \%$ open area while Figure 1 (b) shows a membrane film without backing fabric. As evident from these images, using backing fabric for membrane casting significantly affects the formation of membrane support layer during phase inversion, which may result in the formation of wrinkle and wiggly substrate surface. This is because when a backing fabric with high open area $(25 \%)$ is used, the highly porous mesh offers low resistance to the penetration of polymer solution to the back of the fabric resulting in the formation of air pockets and uneven substrate surface during phase inversion process $[18,23]$. Thus the $T_{2}$ membrane samples could not be utilised for PAO process performance tests since only a small area of the membrane substrate was wrinkle and defect free. This $\mathrm{T}_{2}$ membrane sample was therefore characterised for other properties using a much smaller FO membrane unit with a membrane area of $3 \mathrm{~cm}^{2}$ compared to the PAO unit that required a minimum of $21 \mathrm{~cm}^{2}$. Although the membrane cell size was much smaller however the testing conditions such as DS and FS properties and their 
crossflow velocities were conducted under similar conditions as the other membranes. Due to the difficulty in the formation of wrinkle and defect free membrane support layer using the backing fabric with $25 \%$ open area under both casting methods, membrane samples from $\mathrm{T}_{3}$ to $\mathrm{T}_{5}$ were therefore fabricated using a backing fabric with much less open area (5\%) in order to limit the polymer penetration and solve solving the issue of wrinkle formation. Figure 1(c) shows that the $\mathrm{T}_{3}, \mathrm{~T}_{4}$ and $\mathrm{T}_{5}$ membrane samples casted on backing fabric with a $5 \%$ open area have uniform morphology without any wrinkle or major defect, suggesting that the backing fabric properties such as opening area percentage could have a significant impact on the formation of membrane support layer during phase inversion process. Previous study by Sairam et al. observed similar findings and tried to develop a new method by pasting the woven mesh fabric support on the glass to limit the polymer penetration for fabricating CTA-FO membrane [23]. However, adopting this method in this study using different materials as a paste to block the fabric pores was not successful in fabricating TFC-FO due to detachment of PES substrate from the backing fabric during phase inversion stage.

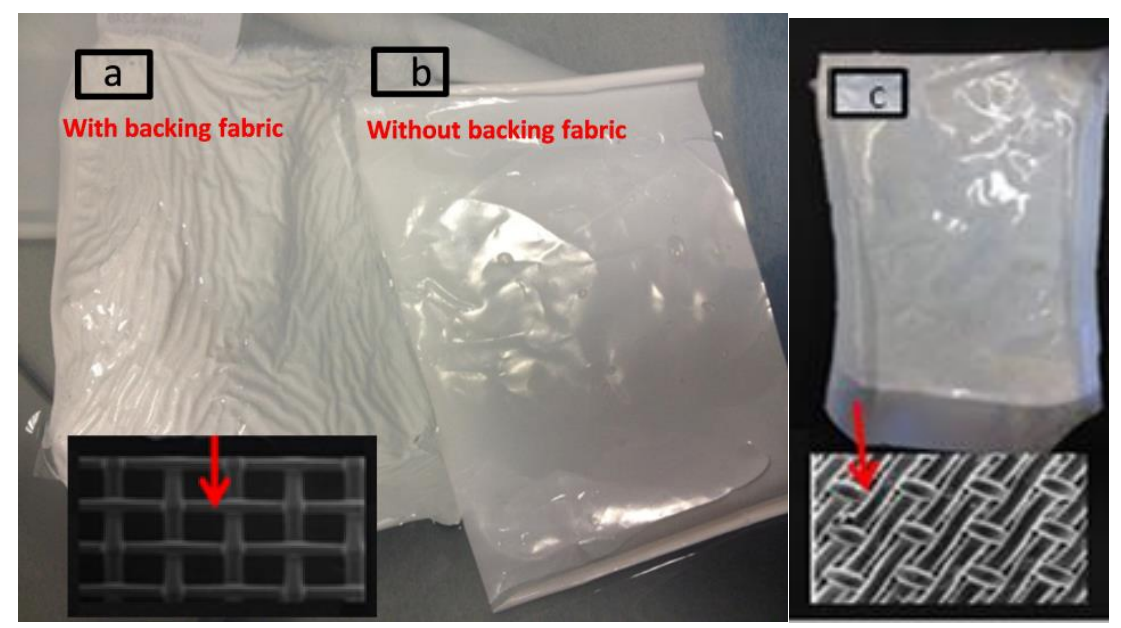

Figure 1. Picture and SEM images of membranes substrate and backing fabrics displaying (a) $\mathrm{T}_{2}$ sample on backing polyester mesh support with $25 \%$ opening prepared by RO-style 
casting method, (b) membrane substrate prepared without a backing fabric and (c) $\mathrm{T}_{3}-\mathrm{T}_{5}$ membrane substrates casted on polyester mesh with 5\% open area by RO-style.

As discussed, several strategies have been developed to mitigate the impact of polymer solution penetration through the backing fabric during the casting of membrane substrate. This includes choosing a unique fabrication method in commercial scale membrane fabrication [18], using a double layer backing fabric [22], and pasting the backing fabric to the glass plate [23]. In this study, however, the PES support layer for the TFC-FO membrane was developed using a woven fabric mesh with low opening percentage (5\% in plane area) and yet with very high water permeability. This approach not only solved the problem of polymer solution penetration during the PES casting by phase inversion but also could improve the membrane mechanical strength to withstand high hydraulic pressure. The backing fabric mesh shows ultrahigh water permeability of $1554 \mathrm{~L} \mathrm{~m}^{-2} \mathrm{~h}^{-1}$ bar $^{-1}$ even though the pore opening area was only $5 \%$ in plane area. This high water permeability is likely due to overlapped fabric knitting with wide side openings at the knit junctions allowing free passage of water through the backing fabric.

\subsubsection{Characterisation of membrane substrates layer}


Figure 2 shows the SEM images of the cross section, top and bottom surfaces of the $\mathrm{T}_{1}$ membrane sample casted through FO-style casting method. This is in fact a unique substrate casting method designed to eliminate wrinkle and defect problems and also to reduce the thickness of the substrate to less than $100 \mu \mathrm{m}$. This membrane fabrication approach is used for manufacturing TFC-FO membranes at a large commercial scale level by preventing polymer penetration through the back of the fabric especially when a dilute polymer solution with higher opening mesh fabric is used [18]. However, the SEM images in Figure 2 show that the bottom and top surface of the $\mathrm{T}_{1}$ substrate sample using FO-style casting method under lab condition had a severe impact on the formation of membrane top and bottom surfaces. The bottom surface (supposed to be the skin layer for rejection layer) was formed containing large pores with sizes ranging from $0.5 \mu \mathrm{m}$ to $1.5 \mu \mathrm{m}$, making it unsuitable for the uniform formation of polyamide rejection layer by interfacial polymerisation.

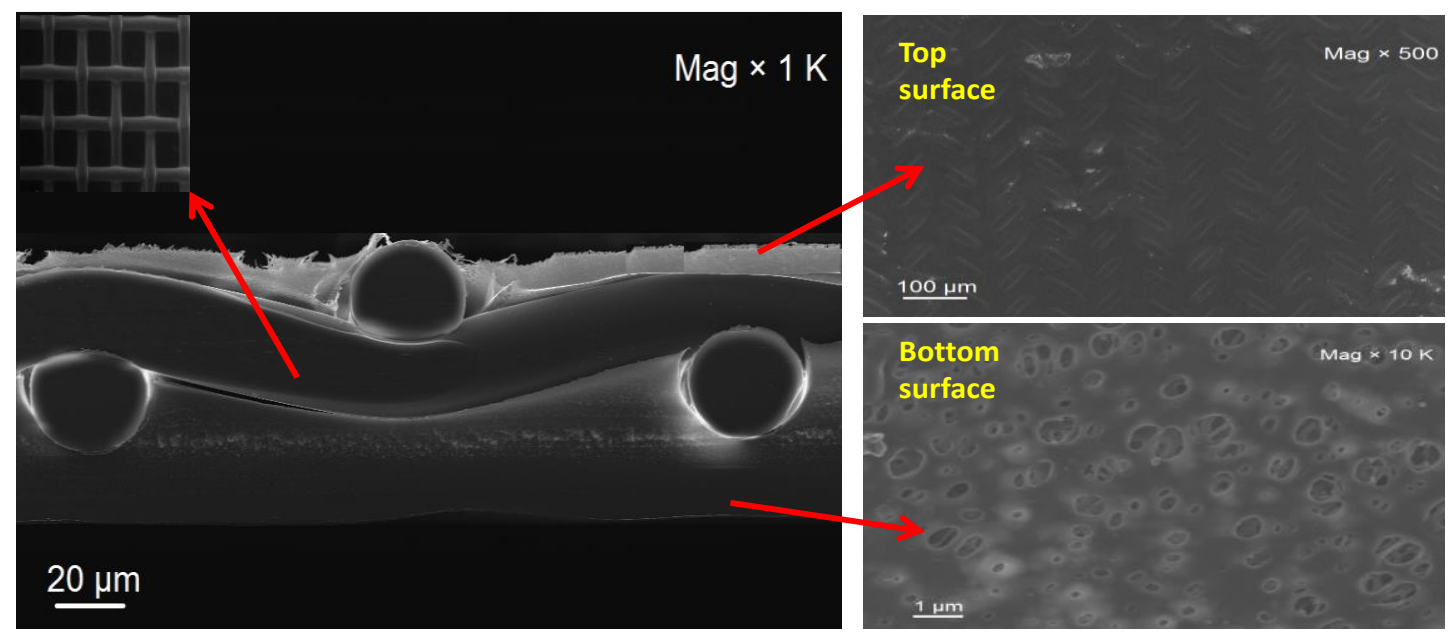

Figure 2. SEM images of $\mathrm{T}_{1}$ membrane substrate displaying cross-section (left image) and the top and bottom surfaces (two right images) casted on woven polyester mesh backing fabric by adopting FO-style casting method.

The SEM images of membrane substrate samples $\mathrm{T}_{3}, \mathrm{~T}_{4}$ and $\mathrm{T}_{5}$ are presented in Figures 3-5, respectively. Figures 3 (a), 4 (a), and 5 (a) present the bottom surface of membrane samples 
$\mathrm{T}_{3}, \mathrm{~T}_{4}, \mathrm{~T}_{5}$ which are fabricated by the RO-style casting method (the $\mathrm{T}_{2}$ sample was discarded since the substrate formed had severe wrinkles as shown in Figure1(a)). It is clear from Figures 3 and 4 that a slight penetration of PES polymer through the backing fabric has occurred for $\mathrm{T}_{3}$ and $\mathrm{T}_{4}$ samples while the polymer penetration was not significant for $\mathrm{T}_{5}$ substrate sample as the woven backing fabric was clearly visible as shown in Figure 5(a). Although the polymer concentrations for $T_{3}$ and $T_{4}$ samples were higher than the $T_{5}$ sample, the pre-treatment of backing fabric for $\mathrm{T}_{3}$ and $\mathrm{T}_{4}$ samples with NMP likely caused a slight penetration. NMP pretreatment is essential for bonding the backing fabric to the PES substrate thereby preventing substrate detachment from the backing fabric. However the residual NMP on the fabric from the pre-treatment can dilute the polymer solution near the bottom surface of the membrane substrate close to the fabric filament subsequently resulting in more porous bottom surface. However, this enhanced porosity could be advantageous for the osmotic process by reducing the ICP effect.

The cross-sectional SEM images of membrane samples $\mathrm{T}_{3}$ and $\mathrm{T}_{4}$ in Figures $3(\mathrm{~b})$ and $4(\mathrm{~b})$ respectively, indicate that the membrane substrate formed has denser but perhaps sponge-like support structures compared to finger-like support structure for membrane sample $\mathrm{T}_{5}$ as shown in Figure 5(b). Several macro-voids formation was observed for substrate sample $\mathrm{T}_{4}$ compared to no clear macro-voids for substrate sample $T_{3}$. The finger-like structure formed for membrane sample $\mathrm{T}_{5}$ is due to the use of lower polymer concentrations ( $12 \%$ compared to $18 \%$ for samples $T_{3}$ and $T_{4}$ ). These results therefore indicate that complete penetration of the polymer solution is affected by polymer solution concentration (or viscosity), fabric pretreatment using MNP and backing fabric properties such as opening area. 

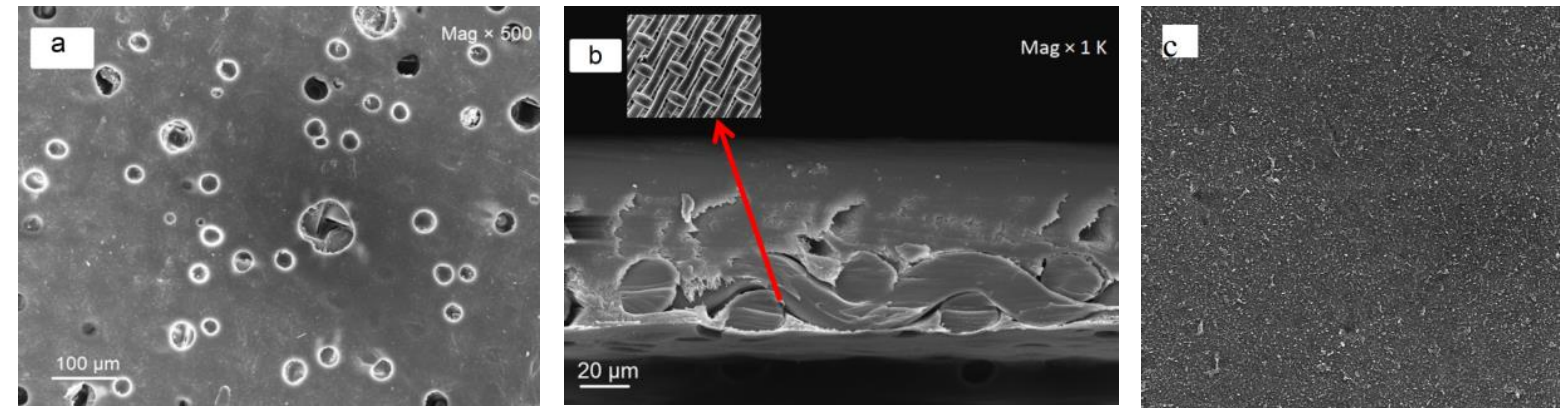

Figure 3. SEM images of $\mathrm{T}_{3}$ membrane substrate displaying (a) bottom surface, (b) crosssection and (c) the top PA rejection layer. The membrane substrate was prepared by a ROstyle casting method on a woven polyester backing fabric (5\% opening).
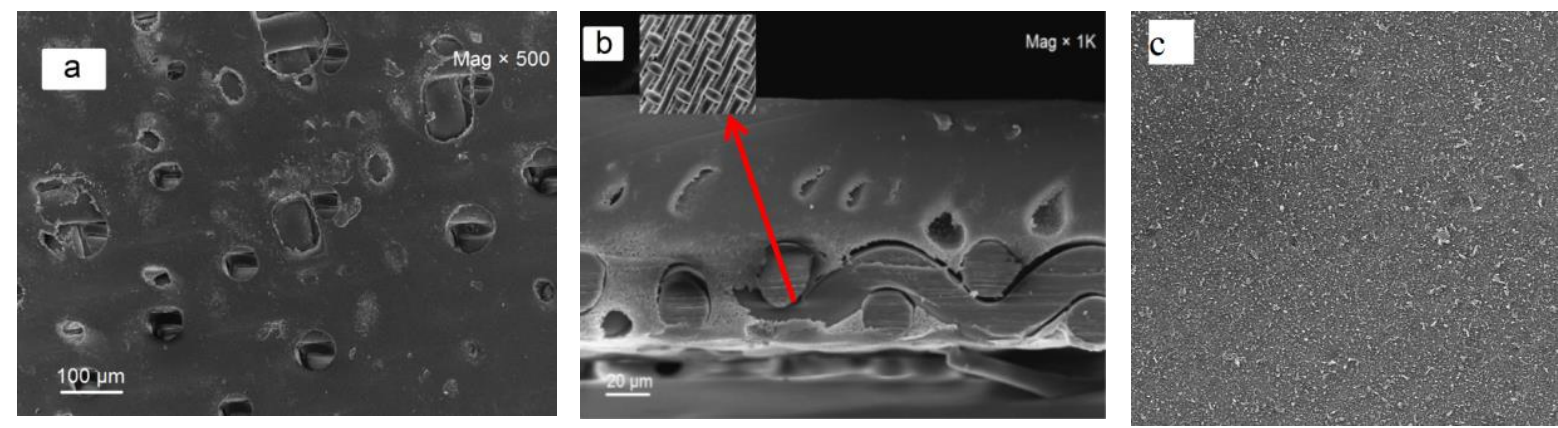

Figure 4. SEM images of $\mathrm{T}_{4}$ membrane substrate displaying (a) bottom surface, (b) crosssection and (c) the top surface of PA rejection layer. The membrane substrate was prepared by a RO-style casting method on a woven polyester backing fabric (5\% opening). 

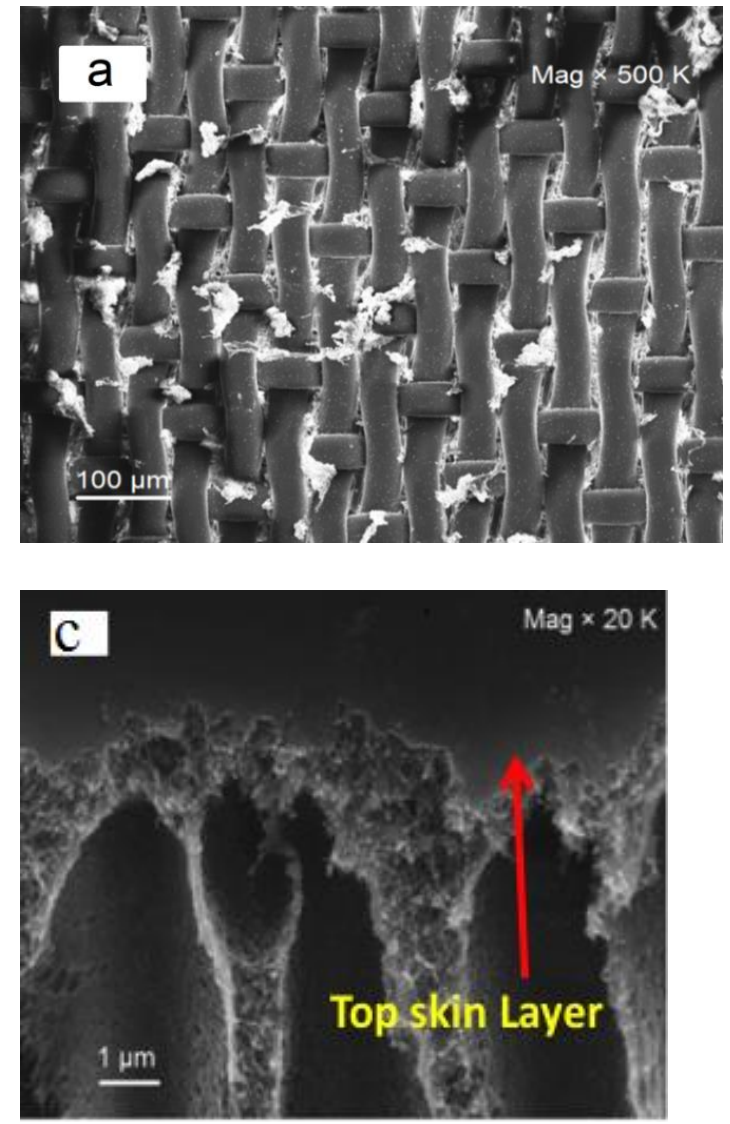
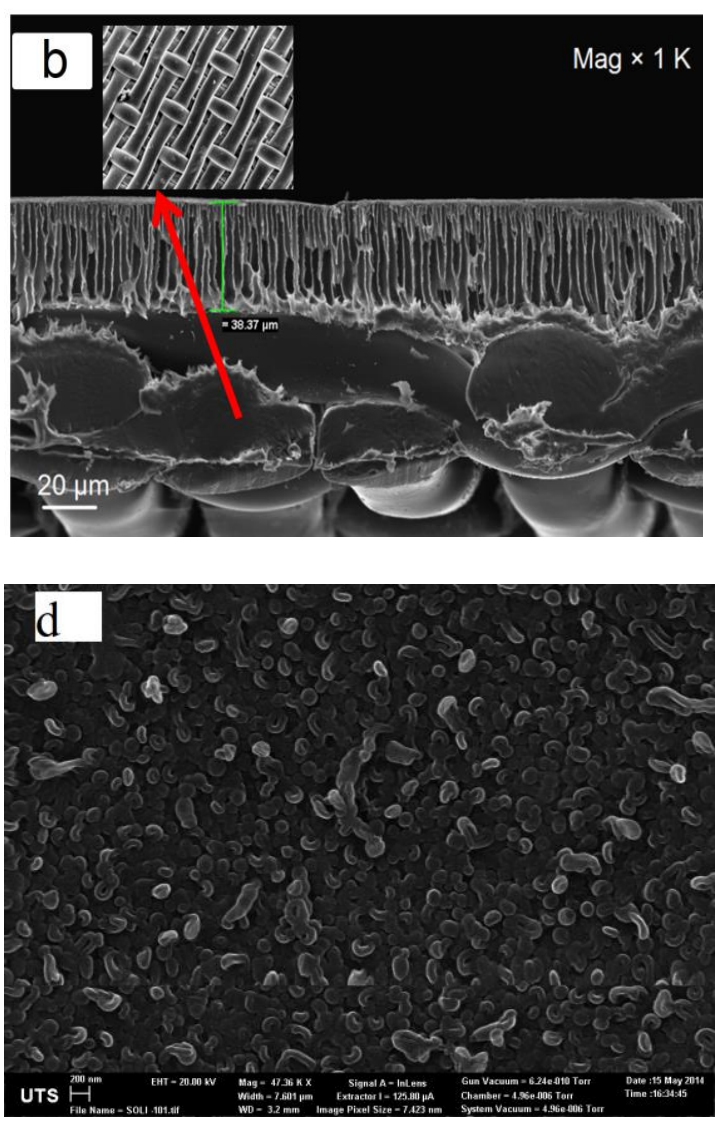

Figure 5. SEM images of $\mathrm{T}_{5}$ membrane substrate displaying (a) bottom surface, (b) overall cross-section, (c) cross-section of top skin layer of the substrate and (d) the top surface of the PA rejection layer. The membrane substrate was prepared by a RO-style casting method on a woven polyester backing fabric (5\% opening). The backing fabric was not pre-treated with NMP solvent prior to casting

Table 2 shows the measured thickness and the effect of applied pressure on the membrane physical properties such as compaction and thickness. $T_{1}$ and $T_{2}$ and $T_{5}$ substrates showed an overall thickness of about $100 \mu \mathrm{m}$ while $\mathrm{T}_{3}, \mathrm{~T}_{4}$ substrates had an overall thickness of about 150 $\mu \mathrm{m}$. After subjecting the membrane samples to the PAO process, the $\mathrm{T}_{3}$ membrane sample was observed to be less compacted than the $\mathrm{T}_{4}$ substrate which may be related to the difference in substrate porosity formed when different concentration of PEG additive as a pore-former was used although this is not clearly visible from the SEM images of Figures 3(b) and 4(b). A higher 
PEG concentration was used for the $\mathrm{T}_{4}$ sample (20\%) as against only $10 \%$ for the $\mathrm{T}_{3}$ sample. At higher PEG concentration, the porosity of $\mathrm{T}_{4}$ substrate is expected to be higher than $\mathrm{T}_{3}$ as the porosity enhances with the PEG concentration [32]. Based on the porosity values in Table 2 obtained by gravimetric analysis, sample $\mathrm{T}_{4}(74 \%)$ showed only slightly higher porosity values than $\mathrm{T}_{3}$ sample (72\%); however the cross-sectional images of sample $\mathrm{T}_{3}$ and $\mathrm{T}_{4}$ indicates that several macro-voids can be observed for $\mathrm{T}_{4}$ substrate not observed in $\mathrm{T}_{3}$ sample, suggesting that this likely resulted in higher compaction of membrane sample $\mathrm{T}_{4}$ under the hydraulic pressure.

Table 2: Characterisation of membrane substrates.

\begin{tabular}{|c|c|c|c|c|c|c|c|c|}
\hline \multirow{2}{*}{$\begin{array}{c}\text { Membrane } \\
\text { sample }\end{array}$} & \multicolumn{2}{|c|}{ Membrane Thickness $(\mu \mathrm{m})$} & \multirow{2}{*}{$\begin{array}{c}\text { Porosity } \\
\text { \% }\end{array}$} & \multicolumn{2}{|c|}{ Contact angle $\left({ }^{\circ}\right)$} & \multirow{2}{*}{$\begin{array}{l}\text { Tensile } \\
\text { strength } \\
\text { (MPa) }\end{array}$} & \multirow{2}{*}{$\begin{array}{l}\text { Young's } \\
\text { Modulus } \\
\text { (MPa) }\end{array}$} & \multirow{2}{*}{$\begin{array}{l}\text { Elongation } \\
\text { break }(\%)\end{array}$} \\
\hline & Fresh & *Used & & $\begin{array}{l}\text { Active } \\
\text { layer }\end{array}$ & $\begin{array}{c}\text { Support } \\
\text { layer }\end{array}$ & & & \\
\hline $\mathrm{T}_{1}$ & $99.3 \pm 3.3$ & NA & $71 \pm 1$ & $54 \pm 1$ & $74 \pm 2$ & & & \\
\hline $\mathrm{T}_{2}$ & $105.2 \pm 3.1$ & NA & $70 \pm 1$ & $51 \pm 3$ & $72 \pm 1$ & & & \\
\hline $\mathrm{T}_{3}$ & $150.2 \pm 3.0$ & $142 \pm 2$ (10 bar) & $72 \pm 1$ & $56 \pm 1$ & $75 \pm 1$ & 148.6 & 1323.2 & 41.7 \\
\hline $\mathrm{T}_{4}$ & $155.3 \pm 1.2$ & $141 \pm 3$ (10 bar) & $74 \pm 1$ & $57 \pm 1$ & $76 \pm 2$ & 111.4 & 1132.8 & 43.3 \\
\hline $\mathrm{T}_{5}$ & $103.2 \pm 3.2$ & $72 \pm 4$ (5 bar) & $79 \pm 3$ & $55 \pm 1$ & $75 \pm 2$ & 84.4 & 749.2 & 45.5 \\
\hline CTA & $103.2 \pm 1.2$ & $102 \pm 3$ (10 bar) & $55 \pm 1$ & $76 \pm 2$ & $81 \pm 3$ & 61.9 & 532.6 & 63.7 \\
\hline WJ-FO & $141.2 \pm 3.6$ & $70 \pm 3$ (2 bar) & $84 \pm 3$ & $65 \pm 1$ & $65 \pm 3$ & 35.8 & 141.7 & 37.8 \\
\hline WJ-RO & $155.2 \pm 2.5$ & $151 \pm 2$ (10 bar) & $61 \pm 1$ & $96 \pm 1$ & $105 \pm 2$ & 25.8 & 90.7 & 41.5 \\
\hline
\end{tabular}

* The thickness of the used membrane was measured after the membrane was subjected to an applied pressure of 2-10 bar depending on substrate tensile strength. 
The results in Table 2 show that the thickness of the commercial WJ-FO membrane was reduced by more than $50 \%$ even at much lower applied pressure of 2 bar. Similarly the thickness of $\mathrm{T}_{5}$ membrane sample was also decreased by about $30 \%$ due to the presence of finger-like structure in the membrane substrate. The membranes with the finger-like structure are vulnerable to compaction even with the slight pressure created by the cross flows $[31,33]$. Based on the results of membrane compaction with $\mathrm{WJ}-\mathrm{FO}$ and $\mathrm{T}_{5}$ membrane samples (both of which have finger-like support layer), we hypothesise that although a membrane with low $S$ value is desirable for higher water flux however lower $S$ values also results in poor mechanical strength essential for withstanding the applied hydraulic pressure. Hence polymeric membrane substrates with highly porous finger-like structures may not be suitable for the pressure based osmotic process such as PAO or PRO processes and hence a more stable membrane specific for PAO process is required. A similar TFC-FO membrane SEM from WJ reported elsewhere was used in this study [34]. In addition, the gravimetric analysis in Table 2 shows that both $\mathrm{T}_{5}$ and WJ-FO membrane substrates have higher porosities of $79 \pm 3 \%$ and $84 \pm 3 \%$, respectively, indicating their lower resistance to membrane compaction. Since the membrane substrate with finger-like structure is more susceptible to compaction under applied pressure, a denser substrate is expected to be more suitable to sustain high hydraulic pressure during the PAO process. The CTA membrane did not show any noticeable change in thickness under applied pressure.

The hydrophilicity of the membrane substrates was evaluated by measuring the contact angle. As presented in Table 2, the contact angle of $\mathrm{T}_{3}$ and $\mathrm{T}_{4}$ membrane substrate samples was $\sim 56^{\circ}$ which is significantly lower than the CTA $\left(\sim 76^{\circ}\right)$ and the WJ-FO $\left(\sim 65^{\circ}\right)$ membrane, indicating that the membrane substrates fabricated in this study were more hydrophilic than the commercial FO membrane. The relatively low contact angles for the $T_{3}$ and $T_{4}$ could be 
attributed to the hydrophilic nature of PES and the addition of PEG in the membrane casting solutions $[16,17]$. Recent studies have shown that, hydrophilicity property of the membrane support layer has a significant influence on the performance of the FO process especially by reducing the ICP effects in the FO process $[26,35]$.

Table 2 also displays the mechanical properties of the membrane substrate samples. The mechanical property of the membrane samples fabricated in this study is better compared to the both commercial FO and even RO membranes in terms of tensile strengths, Young's modulus and the elongation at break except for CTA membrane where its elongation at break was the highest amongst all the tested membrane samples. These results indicate that the membrane samples $\mathrm{T}_{3}$ and $\mathrm{T}_{4}$ are expected to be much more robust than the commercial $\mathrm{RO}$ and FO membranes.

\subsection{Membrane rejection layer}

\subsubsection{Relating substrate morphology to the formation of thin polyamide rejection layer}

The top skin layer and surface pore size of the membrane substrate play a major role in the formation of polyamide rejection layer [19, 36, 37]. Figures 3(c), 4(c) and 5(d) show the SEM images of the defect free surface of the PA rejection layer of their respective membranes. For a better illustration of the rejection layer morphology's requirements and the reason why FO style membrane fabrication for the $T_{1}$ sample was not successful in the lab scale, the $T_{1}$ and $T_{5}$ skin layer samples have been chosen for the purposes of comparison. Figure 5 (c) shows SEM images of the $\mathrm{T}_{5}$ membrane fabricated by RO style casting method. Figure 2 shows the membrane surface (bottom surface) of the $\mathrm{T}_{1}$ sample fabricated by the FO style casting method. Similar to commercial FO membrane fabrication presented [18], the skin layer was in contact with glass plate which leads to large pore size on the membrane bottom surface where the rejection layer is supposed to form. The SEM images of the $\mathrm{T}_{1}$ top and bottom surface together have been shown in Figure 2 in the previous section. 
Generally, polyamide layer forms as a result of MPD solution eruption from the membrane pores and reacts with TMC those results in the formation of a thin skin PA rejection layer. However, in the membrane surface with a large pore size, such as the $T_{1}$ sample, TMC can penetrate the pores and result in PA formation inside the pores and formation of PA layer with uneven thickness increasing the chance of some uncoated area and defect points on the membrane rejection layer [29]. Top skin layers with optimum pore size are critical for optimum rejection layer formation, otherwise membrane rejection will be compromised [38]. It was not possible to fabricate a PA layer on the $\mathrm{T}_{1}$ embedded polyester mesh membrane either on the top or bottom surface of the substrate due to defect point caused by the FO-style casting method and large pore size $(\sim 1 \mu \mathrm{m})$, respectively (Figure 2). Studies suggest that there is a relationship between morphology and rejection surface properties of the PA layer to the top skin pore size [39]. Findings show that surfaces with a smaller pore size will form defect free and a smoother rejection layer compared to surfaces with a larger pore size [40].

The polymer concentration was low for the $\mathrm{T}_{5}$ sample compared to the other substrates (Table 1), however, the top skin layer with a porous sub layer is evidence of liquid-liquid phase separation occurred as it was expected for low polymer concentrations during the phase inversion stage (Figure 5 (c)) [39]. The polymer concentration rate at the membrane top surface became more concentrated as a result of air exposure during the casting. Thus, as it is evident from the image, big pores in the membrane porous sub layer could not extend to the membrane surface.

Gelation usually takes place at high polymer concentrations during phase inversion stage [39]. Thus gelation pathway is expected for membrane samples of $T_{1}-T_{2}$ and $T_{3}-T_{4}$ fabricated with 
higher polymer concentration (Table 1). As evident form the SEM images (Figures 3 and 4), substrates with higher polymer concentrations $(18 \%)$ are less porous and free of finger-like structures. However, gelation may not occur for the membrane bottom layer. In the $T_{1}$ sample (casted via the FO-style casting method), the liquid-liquid phase inversion occurs for the bottom surface which is the last part of the casted membrane to solidify in the precipitation bath. Here, the precipitation pathway intersects the binodal before crossing into the gelation region, causing a lower polymer concentration and an open skin layer with larger pores in the bottom surface (Figure 2) $[19,41]$. This may help to explain the failure of interfacial polymerisation attempt when duplicating the FO membrane fabrication on a commercial scale in $\mathrm{T}_{1}$ membrane sample under lab condition.

\subsubsection{Characterisation of membrane rejection layers}

The intrinsic membrane properties such as water permeability coefficient $(A), \mathrm{NaCl}$ rejection $(R)$ and $\mathrm{NaCl}$ salt permeability coefficient $(B)$, selectivity $(B / A)$ of the TFC membranes samples $\mathrm{T}_{3}, \mathrm{~T}_{4}$ and $\mathrm{T}_{5}$ are presented and compared with commercial CTA-ES, WJ- FO and RO membranes in Table 3 . The $\mathrm{T}_{1}$ and $\mathrm{T}_{2}$ membranes were ignored because their substrate samples failed to form a defect-free rejection layer by interfacial polymerisation.

Based on the results in Table 3, all the three TFC-FO membrane samples $\left(\mathrm{T}_{3}, \mathrm{~T}_{4}\right.$, and $\left.\mathrm{T}_{5}\right)$ exhibited much higher water permeability and better $\mathrm{NaCl}$ rejection than the commercial CTAFO membrane. The water permeability coefficient of $T_{4}$ and $T_{5}$ membranes samples were even higher than the WJ TFC-FO membrane. Since the water permeability coefficient is directly related to the rejection layer, it appears that the polyamide layer formation must have been favourable with smooth and probably with uniform average thickness for $\mathrm{T}_{4}$ and $\mathrm{T}_{5}$ membrane substrate samples compared to $\mathrm{T}_{3}$. At an applied pressure of $10 \mathrm{bar}$ in the $\mathrm{RO}$ testing mode, $\mathrm{T}_{3}$ and $\mathrm{T}_{4}$ membrane samples had a decent $\mathrm{NaCl}$ rejection of around $96 \%$ and $94 \%$, respectively, 
which were much higher than the WJ TFC-FO membrane. Solute rejection is expected to be even better at a higher applied hydraulic pressure [42]. Although $\mathrm{T}_{4}$ membrane sample showed higher water permeability than $\mathrm{T}_{3}$ sample, however, it also possessed greater salt permeability coefficient, thereby reducing the solute rejection rate.

Table 3 also presents the $B / A$ ratio of the membrane samples which is a direct indicator of the selectivity of an FO membrane. Generally, a lower B/A ratio is preferred as larger B/A ratio indicates lower selectivity and is likely to increase reverse diffusion of draw solutes towards the feed solution thereby impacting the process performances $[42,43]$. In the current study, both $\mathrm{T}_{3}$ and $\mathrm{T}_{4}$ had relatively low $\mathrm{B} / \mathrm{A}$ ratios of 9 and $14 \mathrm{kPa}$ respectively compared to 61 for the CTA membrane and 32 for the WJ-FO membrane. This indicates that their superior separation properties alongside high water permeability were achieved by the newly developed membranes. The results in Table 3 for $\mathrm{T}_{3}$ and $\mathrm{T}_{4} \mathrm{PAO}$ membrane samples show that TFC polyamide based membranes can be promising alternatives to the existing CTA-based FO membranes for the PAO process.

Table 3: Properties of fabricated TFC and other commercial membranes.

\begin{tabular}{|c|c|c|c|c|c|c|c|}
\hline $\begin{array}{c}\text { Sample } \\
\text { ID }\end{array}$ & $\begin{array}{c}\text { aPure water } \\
\text { permeability } \\
\text { coefficeint }(A) \\
\mathrm{L} / \mathrm{m}^{2} \mathrm{~h}^{-1} \mathrm{bar}^{-1}\end{array}$ & $\begin{array}{c}\mathrm{NaCl} \\
\text { rejection }(\%)\end{array}$ & $\begin{array}{c}\text { bermeability } \\
\mathrm{B}\left(10^{-8} \mathrm{~m} / \mathrm{s}\right)\end{array}$ & $\begin{array}{c}\mathrm{B} / \mathrm{A} \\
(\mathrm{kPa})\end{array}$ & $\begin{array}{c}\text { FO Water } \\
\text { flux } \\
\left(\mathrm{Lm}^{-2} \mathrm{~h}^{-1}\right)\end{array}$ & $\begin{array}{c}\text { SRSF } \\
\left(\mathrm{gL}^{-1}\right)\end{array}$ & $\begin{array}{c}S \text { value } \\
(\mathrm{mm})\end{array}$ \\
\hline $\mathrm{T}_{3}$ & $2.2 \pm 0.16$ & $96.2 \pm 3.5$ & $5.6 \pm 0.13$ & 9.15 & 5.1 & 1.4 & $2.72 \pm 0.15$ \\
\hline $\mathrm{T}_{4}$ & $3.2 \pm 0.26$ & $94.3 \pm 3.0$ & $14 \pm 0.13$ & 14.2 & 6.7 & 1.6 & $2.21 \pm 0.15$ \\
\hline $\mathrm{T}_{5}$ & $3.3 \pm 0.25$ & $91.2^{\mathrm{c}} \pm 3.0$ & $18 \pm 0.13$ & 18.2 & 11 & 2.1 & $0.72 \pm 0.17$ \\
\hline $\mathrm{CT}$ & $0.91 \pm 0.3$ & $78 \pm 4$ & $16 \pm 13$ & 61 & 9.5 & 2.14 & $0.85 \pm 0.15$ \\
\hline WJ-FO & $2.7 \pm 1.12$ & $85 \pm 1^{\mathrm{d}}$ & $23 \pm 13$ & 32.2 & 13.5 & 1.5 & $0.55 \pm 0.21$ \\
\hline WJ-RO & $1.15 \pm 0.16$ & $96 \pm 5$ & $2.9 \pm 13$ & 9.1 & 1.1 & -- & $16.5 \pm 2.00$ \\
\hline
\end{tabular}

a Evaluated in the RO testing mode over an applied pressure range of 1-10 bar with DI water as feed water.

b Evaluated in the RO testing mode over an applied pressure range of 10 bar for a feed water containing $10 \mathrm{~g} / \mathrm{l} \mathrm{NaCl} \mathrm{except}$ for T5 and WJ-FO membranes where the applied pressure was ${ }^{\mathrm{c}} 5$ and ${ }^{\mathrm{d}} 2 \mathrm{bars}$, respectively using $1 \mathrm{~g} / \mathrm{L} \mathrm{NaCl}$. 
For any osmotic process, the membrane structural parameter $(S)$ is an important parameter that measures the resistivity of the membrane support layer to the diffusion of the draw solute. The low value of the structural parameter is desirable for any osmotic membranes in order to minimize the detrimental effects of ICP during the process operations. The results presented in Table 3 shows that, all the three TFC-FO membrane samples have $S$ values of $2.72 \mathrm{~mm}\left(\mathrm{~T}_{3}\right)$, $\mathrm{T}_{4}(2.21 \mathrm{~mm})$ and $\mathrm{T}_{5}(0.72 \mathrm{~mm})$ which are higher than the CTA-FO $(0.85 \mathrm{~mm})$ and WJ TFCFO $(0.55 \mathrm{~mm})$ membranes although it is significantly lower than TFC-RO membranes (16.5 $\mathrm{mm}$ ). This is expected because the $\mathrm{T}_{3}$ and $\mathrm{T}_{4}$ membrane substrates have lower porosity but higher membrane thickness than the WJ-TFC-FO membrane. Besides, the pore structure of T3 and T4 membrane substrates did not exhibit finger-like structure which could increase the tortuosity of the support layer thereby contributing to higher $S$ values. WJ-RO had the highest $S$ value and this is the main reason for the RO membranes in general for their poor performance in the FO process despite their relatively high water permeability.

FO water flux is presented in Table $3 . \mathrm{T}_{5}$ and $\mathrm{WJ}-\mathrm{FO}$ have the highest $\mathrm{FO}$ water flux due to presence of finger-like structures in the substrate and lower structural parameters compared to $\mathrm{T}_{3}$ and $\mathrm{T}_{4}$ membrane sample. The poor FO performance of the $\mathrm{T}_{4}$ and $\mathrm{T}_{5}$ was due to their denser and thicker substrate, higher $S$ value and the compacted backing fabric support. SRSF was also relatively low for $\mathrm{T}_{4}$ and $\mathrm{T}_{5}$ membrane samples despite a decent salt rejection (RO mode) as presented in Table 3.

In the FO process, FO membrane with a higher $A$ value (water permeability) and lower $S$ value (structural parameter) is favourable for obtaining higher water flux however, for the PAO process, the membrane needs a stable, dense and porous membrane with high water permeability. It seems that unlike the FO, membranes with a higher $S$ value may be necessary for the PAO due to the need to withstand required applied hydraulic pressure during the process although. However, an opportunity likely exists to further improve the water flux through the 
pre-treatment and post-treatment of teh PA layer as conducted on the TFC PRO membrane with macrovoid free support layer $[13,44]$.

\subsection{Performance of membranes under the PAO process}

The water fluxes of the five TFC membranes under the PAO process at different applied pressure $(0-10$ bar) are presented in Figure 6 using $0.5 \mathrm{M} \mathrm{NaCl}$ as DS and DI as FS (Figure 6(a)) or $10 \mathrm{~g} / \mathrm{L} \mathrm{NaCl}$ as FS (Figure 6(b)). It is clear from these results that the introduction of applied pressure in addition to the osmotic pressure driving force has a quite significant enhancement of water flux. The water flux increased linearly with the applied pressure although the net gain in the water flux due to applied pressure was different from each membrane. Using $0.5 \mathrm{M} \mathrm{NaCl}$ as DS and DI as FS, the water flux for the TFC-FO membrane samples $\mathrm{T}_{3}, \mathrm{~T}_{4}$ and $\mathrm{T}_{5}$ was $4.5,6.5$ and $8.0 \mathrm{~L} \mathrm{~m}^{-2} \mathrm{~h}^{-1}$ in the $\mathrm{FO}$ process alone (no applied pressure); however the water flux increased to 32 and $37 \mathrm{Lm}^{-2} \mathrm{~h}^{-1}$ for membrane samples $\mathrm{T}_{3}$ and $\mathrm{T}_{4}$, respectively, at an applied pressure of 10 bar. This translates to an effective gain in water flux of 2.75 and $3.05 \mathrm{~L} \mathrm{~m}^{-2} \mathrm{~h}^{-1}$ bar $^{-1}$ for $\mathrm{T}_{3}$ and $\mathrm{T}_{4}$ membranes respectively as presented in Figure 6 (a). The $T_{5}$ membrane could not sustain hydraulic pressure beyond 4 bar due to substrate compaction and poor mechanical strength however its effective gain in water flux at 3 bar was 3.33 $\mathrm{L} \mathrm{m}^{-2} \mathrm{~h}^{-1} \mathrm{bar}^{-1}$. Similarly, WJ-FO membrane sample could not sustain hydraulic pressure beyond 2 bars. Although the same water flux for CTA-FO membrane increased from about 8.0 $\mathrm{Lm}^{-2} \mathrm{~h}^{-1}$ (at no pressure) to $17 \mathrm{Lm}^{-2} \mathrm{~h}^{-1}$ (at 10 bar) however, the effective gain in water flux was only $0.90 \mathrm{Lm}^{-2} \mathrm{~h}^{-1} \mathrm{bar}^{-1}$ which is lower than the effective gain observed with the $\mathrm{T}_{3}, \mathrm{~T}_{4}$ and $\mathrm{T}_{5}$ membrane samples. The effective gain in water flux was even lower for TFC-RO membrane at $0.3 \mathrm{Lm}^{-2} \mathrm{~h}^{-1} \mathrm{bar}^{-1}$. 


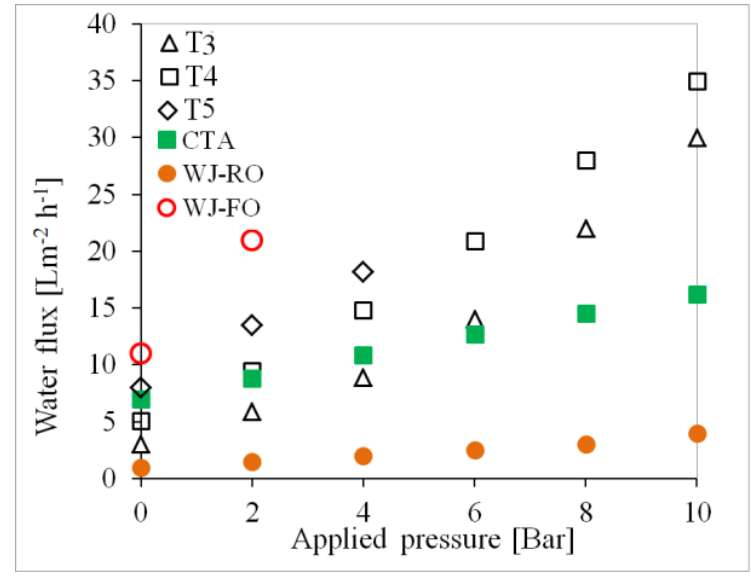

(a)

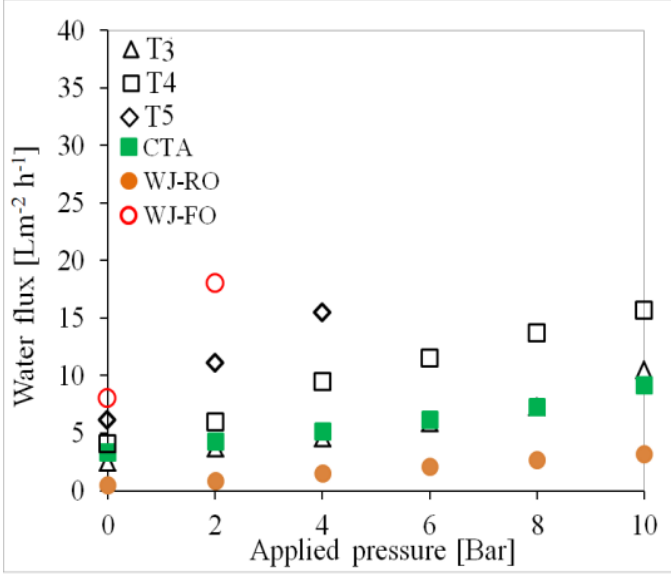

(b)

Figure 6. Performance comparisons of fabricated membranes with commercial membranes in terms of water flux (a) with $0.5 \mathrm{M} \mathrm{NaCl}$ as DS and DI water as FS and (b) $0.5 \mathrm{M} \mathrm{NaCl}$ as DS and BW10 as FS at different applied hydraulic pressure.

The effective gain in water flux for the $T_{3}$ and $T_{4}$ membrane samples was much higher than CTA-FO membrane despite their low water flux in the FO process (no applied pressure). This is likely because of their superior water permeability coefficients of 2.21 for $T_{3}$ and $3.2 \mathrm{Lm}^{-2} \mathrm{~h}^{-}$ ${ }^{1}$ bar $^{-1}$ for $\mathrm{T}_{4}$ as against $0.91 \mathrm{Lm}^{-2} \mathrm{~h}^{-1} \mathrm{bar}^{-1}$ for CTA-FO membrane (Table 3). The low water flux under the FO process alone (no pressure) for $\mathrm{T}_{3}$ and $\mathrm{T}_{4}$ membrane samples can be related to the higher structural parameters of their substrates $\left(\mathrm{T}_{3}=2.72 \mathrm{~mm}, \mathrm{~T}_{4}=2.21 \mathrm{~mm}\right)$ as compacted to $0.85 \mathrm{~mm}$ for CTA-FO membrane. These results therefore indicate that, the PAO process could be more effective using membranes with higher water permeability $(A)$ although higher water flux under the FO process alone too could be certainly more advantageous.

Similar trend in the water fluxes was observed in the PAO process using $0.5 \mathrm{M} \mathrm{NaCl}$ as DS and brackish water $(10 \mathrm{~g} / \mathrm{L} \mathrm{NaCl})$ as the FS as shown in Figure 6(b). However, the water flux is much lower than that using DI as FS, due to decrease in the net driving force caused by the osmotic pressure of FS and ICP. One of the notable observations from Figure 6(b) was that the 
water flux of $\mathrm{T}_{3}$ sample at 10 bar under the PAO process is not significantly high as observed with the DI as feed in Figure 6(a). The water fluxes for $T_{3}\left(2.7 \mathrm{Lm}^{-2} \mathrm{~h}^{-1}\right)$ and CTA $\left(3.0 \mathrm{Lm}^{-2} \mathrm{~h}^{-}\right.$ ${ }^{1}$ ) membrane samples under FO modes (no applied pressure) increased to only about 10.0 and 9.0 $\mathrm{Lm}^{-2} \mathrm{~h}^{-1}$ which translates to an effective flux gain of only 0.73 and $0.60 \mathrm{Lm}^{-2} \mathrm{~h}^{-1} \mathrm{bar}^{-1}$ under the PAO process for $\mathrm{T}_{3}$ and CTA FO membrane samples, respectively. This is perhaps attributed to the role of the ECP now acting on the active layer side of the membrane facing the $\mathrm{NaCl}$ feed solution that reduces the effective driving force, thereby limiting the water flux . However, the water flux for $\mathrm{T}_{4}$ membrane sample increased to about $16 \mathrm{Lm}^{-2} \mathrm{~h}^{-1}$ at $10 \mathrm{bar}$ from a 4.0 $\mathrm{Lm}^{-2} \mathrm{~h}^{-1}$ under the FO mode (no applied pressure) with an effective flux gain of 1.20 $\mathrm{Lm}^{-2} \mathrm{~h}^{-1}$ bar $^{-1}$ which is greater than $\mathrm{T}_{3}$ and CTA-FO membranes. However, the results in Figure 7 indicate that the $\mathrm{T}_{3}$ and $\mathrm{T}_{4}$ have better performance under the PAO process in terms of effective flux gain (specific water flux) compared to CTA membrane. The higher performances under the PAO process for $\mathrm{T}_{3}$ and $\mathrm{T}_{4}$ membranes can be attributed to membrane properties such as higher hydrophilicity, porosity, higher water permeability coefficient and better rejection property despite having higher $S$ values compared to CTA membrane.

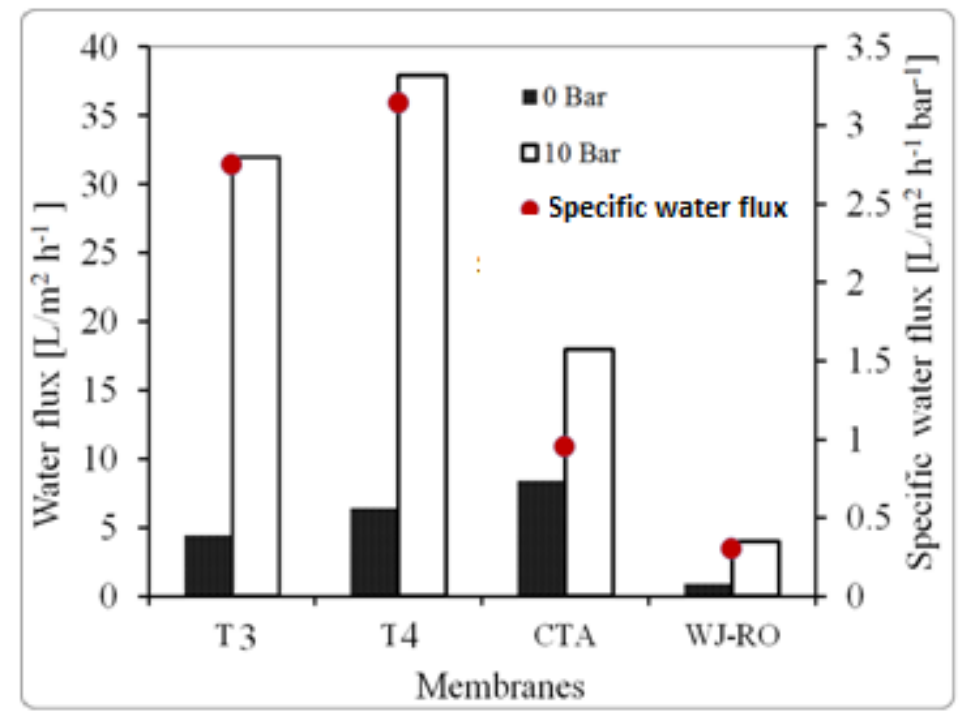


Figure 7.Variation of water flux in the fabricated membrane with commercial membranes with $0.5 \mathrm{M} \mathrm{NaCl}$ as DS and DI water as FS at an applied pressure of 0 and 10 bar.

The solute fluxes across the semipermeable FO membrane are usually assessed in terms of salt rejection for feed solutes which has been presented in the previous section 3.3 (Table 2) and reverse solute flux (RSF) or specific reverse solute flux (SRSF) for draw solutes in the osmotic process. The SRSF is calculated as a ratio $\left(\mathrm{SRSF}=J_{\mathrm{S}} / J_{\mathrm{w}}\right)$ of reverse draw solute flux $\left(J_{\mathrm{S}}\right)$ and the water flux $\left(J_{\mathrm{w}}\right)$ and it basically relates to the reverse flux selectivity of the FO membrane, an important membrane properties to measure the loss of draw solutes during the osmotic process which has economic, environmental and process performance implications. It is clearly evident from Figure 8 that the SRSF generally decreases with the increase in the applied pressure for all the membrane samples tested in the study. Similar results have been confirmed through a previous study on the PAO process which is in contrast to the conventional FO process $[9,12]$. The reverse solute flux is basically a function of the effective concentration differences at the membrane surface and the membrane salt rejection properties. Assuming that the RSF is not significantly affected by the pressure, increasing the applied pressure enhances the water flux thereby lowering the SRSF. It is also likely that, the RSF ( Js) itself must be lowered in the PAO process compared to the FO process due to increase in the convective water flux opposite to the draw solute movement [26]. However, it is difficult to determine the RSF value in the PAO process because of the uncertainty in determining the fraction of PAO water flux that is contributed entirely due to the osmotic pressure difference because of the likely change in the ECP and ICP concentration profile when pressure is applied.

The SRSF for $\mathrm{NaCl}$ as DS and DI as FS for the PAO experiments at pressures ranging from 0 to 10 bar is presented in Figure 8 . The SRSF of the $\mathrm{T}_{3}$ and $\mathrm{T}_{4}$ membrane samples under the FO process $(\Delta P=0)$ was $1.4 \mathrm{~g} / \mathrm{L}$ and $1.60 \mathrm{~g} / \mathrm{L}$, respectively, which are significantly lower than the 
CTA-FO membrane of $2.1 \mathrm{~g} / \mathrm{L}$. These SRSF values of the T3 and T4 membranes are higher than the reported TFC synthesised in the lab where the values lower than $0.5 \mathrm{~g} / \mathrm{L}$ have been reported. However, the SRSF decreases to $0.18 \mathrm{~g} / \mathrm{L}$ and $0.20 \mathrm{~g} / \mathrm{L}$ for $\mathrm{T}_{3}$ and $\mathrm{T}_{4}$ respectively with the applied hydraulic pressure of 10 bar which is still lower than the CTA-FO membrane at $0.62 \mathrm{~g} / \mathrm{L}$. This smaller SRSF of $\mathrm{T}_{3}$ and $\mathrm{T}_{4}$ membrane samples is likely due to the high permeability and higher rejection rates compared to the CTA-FO membrane.

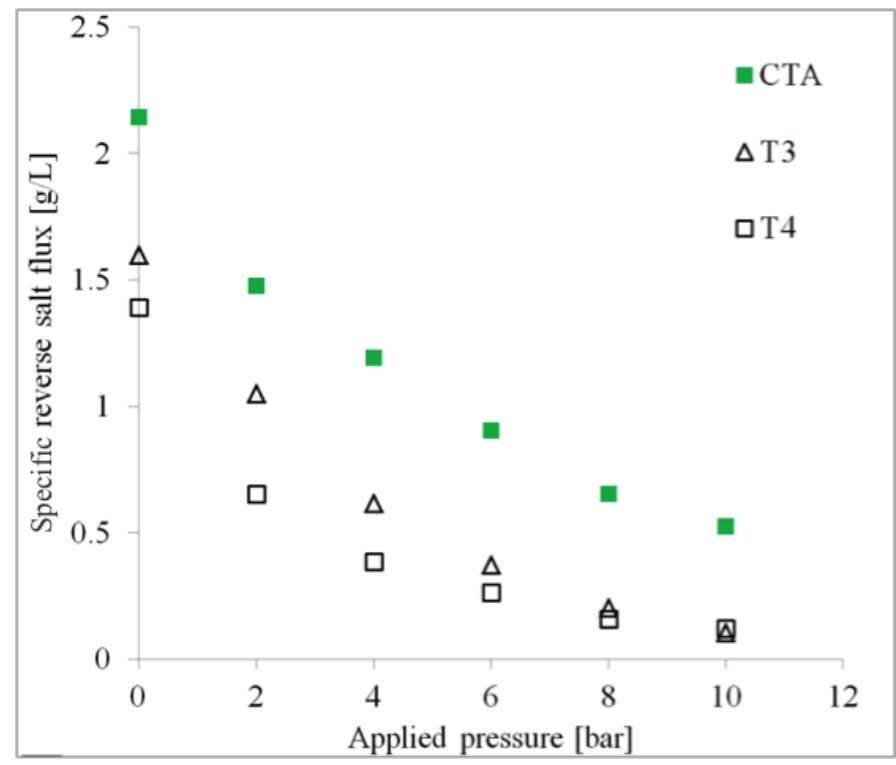

Figure 8. Variations of reverse salt flux at different applied pressures in the PAO process using $0.5 \mathrm{M} \mathrm{NaCl}$ as DS and DI water as FS.

\section{Conclusions}

In this study, polyamide-based TFC membrane with PES substrate was fabricated for the PAO process using two woven polyester meshes of different opening areas as backing fabric and their performances were compared with commercial CTA and TFC WJ-FO membranes. The membrane substrates reinforced by woven mesh fabric were free of wrinkle formation and finger-like structure. The formed TFC membranes possess properties which are suitable for the PAO process. The following conclusions have been drawn from this study: 
- Although membranes with high substrate porosity and finger-like pore structures perform well in the FO process, however they were found less suitable for the PAO process due to compaction and poor mechanical strength when subjected to applied pressure.

- The TFC membranes prepared from the substrates with higher PES polymer concentrations and lower opening backing fabric generally have a sponge-like support structure and high structural parameter ( $S$ value), they performed much better under the PAO process because of their high pure water permeability coefficient $(A)$ and strength.

- Unlike the FO process where membranes with low structural parameter is appropriate however, for PAO process membrane with higher structure parameter is essential to provide adequate mechanical strength to withstand hydraulic pressure. The TFC-FO membrane samples $\mathrm{T}_{3}$ and $\mathrm{T}_{4}$ casted by the RO-style method on a backing fabric with $5 \%$ opening resulted in the highest $S$ values of $2.7 \mathrm{~mm}$ and $2.2 \mathrm{~mm}$ compared to commercial FO membranes of 0.85 (CTA-FO) and 0.55 (WJ TFC-FO).

- Although the TFC-FO membrane samples $\mathrm{T}_{3}$ and $\mathrm{T}_{4}$ had lower water fluxes under the FO process ( $0.5 \mathrm{M} \mathrm{NaCl}$ as DS and DI as FS) compared to commercial FO membranes, their water fluxes under the PAO process reached 33 and $37 \mathrm{Lm}^{-2} \mathrm{~h}^{-1}$ at 10 bar applied pressure with an effective gain in specific water flux of 2.75 and $3.05 \mathrm{Lm}^{-2} \mathrm{~h}^{-1} \mathrm{bar}^{-1}$, respectively. An effective gain of only $0.91 \mathrm{Lm}^{-2} \mathrm{~h}^{-1}$ was obtained by the commercial CTA-FO membrane. WJ TFC-FO membrane could not sustain applied pressure above 2 bar.

- The SRSF of the TFC-FO membrane samples $\mathrm{T}_{3}$ and $\mathrm{T}_{4}$ was much lower than the commercial CTA-FO membrane which significantly decreased to only about 0.18 and 
$0.20 \mathrm{~g} / \mathrm{L}$ compared to $0.61 \mathrm{~g} / \mathrm{L}$ for CTA-FO membrane under the PAO process at 10 bar.

- The PAO process requires a membrane that can endure applied hydraulic pressure and therefore membranes with denser and yet porous and permeable substrate and perhaps free of finger-like structures reinforced by backing fabric is essential.

\section{Acknowledgments}

This study was supported by the Australian Research Council (ARC) Discovery Projects (DP140100835) and the National Centre of Excellence in Desalination Australia (NCEDA), which is funded by the Australian Government through the Water for the Future initiative. This porject was also partically supported under QNRF (NPRP9-052-2-020), ARC future fellowship (FT140101208) and UTS Chancellors postdoctoral research fellowship.

\section{References}

1. S. Zhao, L. Zou, C.Y. Tang, and D. Mulcahy, Recent developments in forward osmosis: Opportunities and challenges, J. Membr. Sci. 396 (2012) 1-21.

2. R.W. Holloway, A.E. Childress, K.E. Dennett, and T.Y. Cath, Forward osmosis for concentration of anaerobic digester centrate, Water Research. 41 (2007) 4005-4014.

3. S. Phuntsho, H.K. Shon, T. Majeed, I. El Salibya, S. Vigneswarana, J. Kandasamy, S. Hong, and S. Leeb, Blended fertilisers as draw solutions for fertiliser drawn forward osmosis desalination, Environ. Sci. Technol. 46 (2012) 4567-4575.

4. A. Achilli, T.Y. Cath, E.A. Marchand, and A.E. Childress, The forward osmosis membrane bioreactor: A low fouling alternative to MBR processes, Desalination. 239 (2009) 10-21.

5. T.-S. Chung, X. Li, R.C. Ong, Q. Ge, H. Wang, and G. Han, Emerging forward osmosis (FO) technologies and challenges ahead for clean water and clean energy applications, Current Opinion in Chemical Engineering. 1 (2012) 246-257.

6. J.R. McCutcheon, R.L. McGinnis, and M. Elimelech, Desalination by ammonia-carbon dioxide forward osmosis: Influence of draw and feed solution concentrations on process performance, J. Membr. Sci. 278 (2006) 114-123.

7. Q. Ge, M. Ling, and T.-S. Chung, Draw solutions for forward osmosis processes: Developments, challenges, and prospects for the future, J. Membr. Sci. 442 (2013) 225-237. 
8. E.M. Garcia-Castello, J.R. McCutcheon, and M. Elimelech, Performance evaluation of sucrose concentration using forward osmosis, J. Membr. Sci. 338 (2009) 61-66.

9. G. Blandin, A.R.D. Verliefde, C.Y. Tang, A.E. Childress, and P. Le-Clech, Validation of assisted forward osmosis (AFO) process: Impact of hydraulic pressure, J. Membr. Sci. 447 (2013) 1-11.

10. B.D. Coday, D.M. Heil, P. Xu, and T.Y. Cath, Effects of Transmembrane Hydraulic Pressure on Performance of Forward Osmosis Membranes, Environ. Sci. Technol. 47 (2013) 2386-2393.

11. T. Yun, Y.-J. Kim, S. Lee, S. Hong, and G.I. Kim, Flux behavior and membrane fouling in pressure-assisted forward osmosis, Desalination and Water Treatment. (2013) 1-6.

12. Y. Oh, S. Lee, M. Elimelech, S. Lee, and S. Hong, Effect of hydraulic pressure and membrane orientation on water flux and reverse solute flux in pressure assisted osmosis, J. Membr. Sci. 465 (2014) 159-166.

13. G. Han, S. Zhang, X. Li, and T.-S. Chung, High performance thin film composite pressure retarded osmosis (PRO) membranes for renewable salinity-gradient energy generation, J. Membr. Sci. 440 (2013) 108-121.

14. S. Chou, R. Wang, and A.G. Fane, Robust and High performance hollow fiber membranes for energy harvesting from salinity gradients by pressure retarded osmosis, J. Membr. Sci. 448 (2013) 44-54.

15. N.Y. Yip, A. Tiraferri, W.A. Phillip, J.D. Schiffman, L.A. Hoover, Y.C. Kim, and M. Elimelech, Thin-Film Composite Pressure Retarded Osmosis Membranes for Sustainable Power Generation from Salinity Gradients, Environ. Sci. Technol. 45 (2011) 4360-4369.

16. K.Y. Wang, T.-S. Chung, and G. Amy, Developing thin-film-composite forward osmosis membranes on the PES/SPSf substrate through interfacial polymerization, AlChE J. 58 (2012) 770-781.

17. N. Widjojo, T.-S. Chung, M. Weber, C. Maletzko, and V. Warzelhan, The role of sulphonated polymer and macrovoid-free structure in the support layer for thin-film composite (TFC) forward osmosis (FO) membranes, J. Membr. Sci. 383 (2011) 214223.

18. J. Herron, Asymmetric forward osmosis membranes. 2008, Google Patents.

19. A. Tiraferri, N.Y. Yip, W.A. Phillip, J.D. Schiffman, and M. Elimelech, Relating performance of thin-film composite forward osmosis membranes to support layer formation and structure, J. Membr. Sci. 367 (2011) 340-352.

20. Y. Yu, S. Seo, I.-C. Kim, and S. Lee, Nanoporous polyethersulfone (PES) membrane with enhanced flux applied in forward osmosis process, J. Membr. Sci. 375 (2011) 6368.

21. C. Qiu, L. Setiawan, R. Wang, C.Y. Tang, and A.G. Fane, High performance flat sheet forward osmosis membrane with an NF-like selective layer on a woven fabric embedded substrate, Desalination. 287 (2012) 266-270.

22. R. McGinnis and G. McGurgan, Forward osmosis membranes. 2013, Google Patents.

23. M. Sairam, E. Sereewatthanawut, K. Li, A. Bismarck, and A. Livingston, Method for the preparation of cellulose acetate flat sheet composite membranes for forward osmosis-desalination using MgSO 4 draw solution, Desalination. 273 (2011) 299307.

24. N.Y. Yip, A. Tiraferri, W.A. Phillip, J.D. Schiffman, and M. Elimelech, High performance thin-film composite forward osmosis membrane, Environmental Science \& Technology. 44 (2010) 3812-3818. 
25. P. Sukitpaneenit and T.-S. Chung, Molecular elucidation of morphology and mechanical properties of PVDF hollow fiber membranes from aspects of phase inversion, crystallization and rheology, J. Membr. Sci. 340 (2009) 192-205.

26. S. Sahebi, S. Phuntsho, J. Eun Kim, S. Hong, and H. Kyong Shon, Pressure assisted fertiliser drawn osmosis process to enhance final dilution of the fertiliser draw solution beyond osmotic equilibrium, J. Membr. Sci.

27. K.L. Lee, R.W. Baker, and H.K. Lonsdale, Membranes for power generation by pressure-retarded osmosis, J. Membr. Sci. 8 (1981) 141-171.

28. S. Loeb, L. Titelman, E. Korngold, and J. Freiman, Effect of porous support fabric on osmosis through a Loeb-Sourirajan type asymmetric membrane, J. Membr. Sci. 129 (1997) 243-249.

29. C. Tabg, C. Qiu, J. Wei, R. Wang, and A.G. Fane, Forward osmosis membrane and method of forming a forward osmosis membrane, (2014), Google Patents, WO2012102680 A1.

30. S.H. Lee, Y.B. Yu, and S.K. Seo, Forward osmosis membranes and method for fabricating the same, (2012), Google Patents, US20120012520 A1.

31. X. Li, S. Zhang, F. Fu, and T.-S. Chung, Deformation and reinforcement of thin-film composite (TFC) polyamide-imide (PAI) membranes for osmotic power generation, J. Membr. Sci. 434 (2013) 204-217.

32. P. Sukitpaneenit and T.-S. Chung, High performance thin-film composite forward osmosis hollow fiber membranes with macrovoid-free and highly porous structure for sustainable water production, Environ. Sci. Technol. 46 (2012) 7358-7365.

33. B. Chakrabarty, A. Ghoshal, and M. Purkait, Preparation, characterization and performance studies of polysulfone membranes using PVP as an additive, J. Membr. Sci. 315 (2008) 36-47.

34. W. Fam, S. Phuntsho, J.H. Lee, and H.K. Shon, Performance comparison of thin-film composite forward osmosis membranes, Desalination and Water Treatment. 51 (2013) 6274-6280.

35. J.R. McCutcheon and M. Elimelech, Influence of concentrative and dilutive internal concentration polarization on flux behavior in forward osmosis, Journal of Membrane Science. 284 (2006) 237-247.

36. C.Y. Tang, Y.-N. Kwon, and J.O. Leckie, Effect of membrane chemistry and coating layer on physiochemical properties of thin film composite polyamide RO and NF membranes: I. FTIR and XPS characterization of polyamide and coating layer chemistry, Desalination. 242 (2009) 149-167.

37. J.G. Wijmans, J. Kant, M.H.V. Mulder, and C.A. Smolders, Phase separation phenomena in solutions of polysulfone in mixtures of a solvent and a nonsolvent: relationship with membrane formation, Polymer. 26 (1985) 1539-1545.

38. R.J. Petersen, Composite reverse osmosis and nanofiltration membranes, J. Membr. Sci. 83 (1993) 81-150.

39. P.S. Singh, S.V. Joshi, J.J. Trivedi, C.V. Devmurari, A.P. Rao, and P.K. Ghosh, Probing the structural variations of thin film composite RO membranes obtained by coating polyamide over polysulfone membranes of different pore dimensions, J. Membr. Sci. 278 (2006) 19-25.

40. A.K. Ghosh and E.M.V. Hoek, Impacts of support membrane structure and chemistry on polyamide-polysulfone interfacial composite membranes, J. Membr. Sci. 336 (2009) 140-148.

41. H. Bokhorst, F.W. Altena, and C.A. Smolders, Formation of asymmetric cellulose acetate membranes, Desalination. 38 (1981) 349-360. 
42. C.Y. Tang, Q. She, W.C.L. Lay, R. Wang, and A.G. Fane, Coupled effects of internal concentration polarization and fouling on flux behavior of forward osmosis membranes during humic acid filtration, J. Membr. Sci. 354 (2010) 123-133.

43. D. Xiao, C.Y. Tang, J. Zhang, W.C.L. Lay, R. Wang, and A.G. Fane, Modeling salt accumulation in osmotic membrane bioreactors: Implications for FO membrane selection and system operation, J. Membr. Sci. 366 (2011) 314-324.

44. Y. Cui, X.-Y. Liu, and T.-S. Chung, Enhanced osmotic energy generation from salinity gradients by modifying thin film composite membranes, Chem. Eng. J. 242 (2014) 195-203. 